\title{
EL FETICHISMO DE LA REALIDAD. UNA INTERPRETACIÓN DE AGUSTÍN GARCÍA CALVO A TRAVÉS DE MARX Y NIETZSCHE
}

\author{
Javier Arkotxa Sarralde \\ Universidad del País Vasco/Euskal Herriko Unibertsitatea \\ javiarkotxa@gmail.com
}

\begin{abstract}
RESUMEN
El objetivo de este artículo es tratar de comprender uno de los aspectos fundamentales de la obra de Agustín García Calvo, su crítica a la Realidad, a través del pensamiento de Marx y Nietzsche. El autor sostiene que la obra de García Calvo realiza un original aprovechamiento de las críticas de Marx y Nietzsche y puede servir como herramienta de interpretación del presente. Esto es, en definitiva, lo que este artículo trata de mostrar, afirmando que, tal como Marx teorizó sobre el fetichismo de la mercancía y Nietzsche utilizó también el término 'fetichismo' para referirse a los procesos lingüísticos, García Calvo expuso, en su ataque a la Realidad, algo que podríamos describir como fetichismo de la Realidad.
\end{abstract}

Palabras clave: García Calvo, Nietzsche, Marx, fetichismo, cosificación.

\section{REALITY FETISHISM. AN INTERPRETATION OF AGUSTÍN GARCÍA CALVO THROUGH MARX AND NIETZSCHE}

Abstract

The aim of this article is to try to understand one of the fundamental aspects of the work of Agustín García Calvo, his criticism of Reality, through the thought of Marx and Nietzsche. The author asserts that the work of García Calvo makes an original use of the criticisms of Marx and Nietzsche and can be used as a tool of interpretation of the present. This is, in short, what this article tries to show, claiming that, as Marx theorized about the commodity fetishism and Nietzsche used also the term 'fetishism' to refer to linguistic processes, García Calvo stated, in his attack to Reality, something that we can describe as Reality fetishism.

Keywords: García Calvo, Nietzsche, Marx, fetishism, reification. 


\section{INTRODUCCIÓN}

Seis años han pasado ya desde que nos dejó Agustín García Calvo, uno de los pensadores más prolíficos e interesantes que nos ha dejado el panorama filosófico español del siglo xx. Parece, por tanto, el momento idóneo para hacer frente al reto que se nos presenta a los amantes y estudiosos de la filosofía familiarizados con su obra: interpretar, comprender, poner en discusión y hacer balance de su aportación y potencialidad. No es otro, en verdad, el objetivo de este artículo.

No obstante, parece evidente que la obra de García Calvo presenta ciertas dificultades a la hora de definir con exactitud su propuesta y de ser situada dentro de una corriente filosófica concreta, la cual ha sido definida como nietzscheana y no-filosófica ${ }^{1}$, como descripcionismo gnoseológico ${ }^{2}$, anarquismo lingüístico ${ }^{3}$, ha sido comparada con el postestructuralismo francés ${ }^{4}$, etc. Una dificultad añadida supone el singular estilo y vocabulario utilizado por el zamorano, quien, reivindicando la razón y el lenguaje comunes, se negó a utilizar todo tipo de jergas académicas o filosóficas, lo que conlleva que, por querer ser fieles a su propuesta y a su -por otra parte- magistral estilo, muchos intérpretes nos hayamos limitado a exponer su pensamiento en sus mismos términos, siendo esta interpretación nada más que una simple repetición $-\mathrm{y}$ no, por tanto, interpretación real y discusión críticade las ideas que ya se encuentran en las obras de García Calvo.

Dicho esto, el objetivo de este artículo es tratar de comprender uno de los aspectos fundamentales de la obra de García Calvo, su crítica a la Realidad, a través del pensamiento de Marx y Nietzsche. Considero, pues, que leer a García Calvo a través de dos autores clásicos de la filosofía puede servir para situar a este en necesaria discusión con otros pensadores y a arrojar luz sobre su obra, no solo, precisamente, para estudiarlo como «objeto» filosófico y para integrarlo dentro de la Historia y del contexto de la Realidad -como él, acaso, diría-, sino porque su análisis bifacético de la Realidad -como lenguaje y como Dinero- realiza un original aprovechamiento de las críticas que Marx y Nietzsche llevan a cabo y puede servir como herramienta de interpretación del presente. Esto es, en definitiva, lo que este artículo tratará de mostrar, afirmando que, tal como Marx teorizó sobre el fetichismo de la mercancía y Nietzsche utilizó también el término 'fetichismo' para referirse

1 Bueno, G. 1978 - Gustavo Bueno es entrevistado por Sanchez Dragó- La Filosofía en España TVE junio 1978, 2013 (1978). Recuperado de https://www.youtube.com/watch?v=UhZX3wgJ9d4.

2 Bonilla, J. «El concepto de pueblo en la obra de Agustín García Calvo», Cuadernos hispanoamericanos. Madrid, núm. 789, marzo 2016, pp. 86-105.

3 Carretero Ajo, A.J. «El anarquismo lingüístico y sin fin de Agustín», Periódico Cnt, núm. 395, diciembre 2012, p. 16. Recuperado de http://www.cnt.es/periodico/peri\%C3\%B3dico-cnt-n\%C2\%BA-395, diciembre-2012.

${ }^{4}$ García Maciá, G. De la desficcionalización ontológica al anonimato: el postestructuralismo hispano a través de Agustín García Calvo (tesis doctoral). Universidad de Granada, Granada, 2015. 
a los procesos lingüísticos 5 , García Calvo expuso, en su ataque a la Realidad, algo que podríamos describir como fetichismo de la Realidad.

\section{BREVE APUNTE SOBRE EL FETICHISMO EN MARX Y NIETZSCHE}

Antes de empezar a analizar directamente la obra de García Calvo, valga este breve capítulo como aclaración de lo que se entiende por fetichismo en las obras de Marx y Nietzsche.

Brevemente, tanto Marx como Nietzsche, siguiendo a la crítica a la religión de Feuerbach que ambos conocieron -quien rebaja «la teología al estado de antropología ${ }^{7}-$, tratan también de mostrar el carácter social oculto que tanto la mercancía como la verdad tienen, respectivamente. Con respecto a Marx, este fenómeno «inseparable de la producción mercantil ${ }^{8}$ genera que la mercancía y el mundo mercantil se le aparezcan al ser humano como algo ajeno a su praxis, natural y objetivo, que, asimismo, se le impone irremediablemente como algo exterior. Este fenómeno, y la dominación abstracta que esto supone, se derivarían de las relaciones básicas del capitalismo constituidas por el trabajo abstracto'. Siendo conciso, es el hecho de que la producción esté destinada al intercambio lo que genera que sean las mercancías, al relacionarse «socialmente» en el mercado, las que terminen dirigiendo la economía sin el menor control de los seres humanos y apareciéndoseles «como una relación social entre los objetos, existente al margen de los productores ${ }^{10}$.

De manera similar, Nietzsche critica también que el ser humano olvida el carácter social, histórico y lingüístico que las verdades tienen, pues estas son convenciones creadas por el ser humano al querer vivir en sociedad ${ }^{11}$. En este proceso, el ser humano se vale del lenguaje para abstraer las diferencias individuales entre los estímulos que recibe y crear los conceptos. Así pues, la verdad es presentada por

5 Nietzsche, F. Crepúsculo de los ídolos. Alianza, Madrid, 2017 (1888), «La “razón” en la filosofía», $\$ 5$, p. 67.

${ }^{6}$ Si bien Nietzsche no elabora una teoría del fetichismo como tal, el uso literal que hace del término (véase nota anterior) y las similitudes con la teoría marxiana sugieren que se puede hablar de un fetichismo del lenguaje y la verdad en la obra nietzscheana. Estas similitudes las he desarrollado en un artículo titulado "Del fetichismo de la mercancía al fetichismo del lenguaje y la verdad. Un diálogo entre Marx y Nietzsche», en Chillón, J.M. Martínez, Á. y Frontela, P. (eds.), Hombre y logos: antropología y comunicación. Editorial Fragua, Madrid, 2019, pp. 237-248.

7 Feuerbach, L. La esencia del cristianismo, Trotta, Madrid, 2003 (1841), p. 43.

${ }^{8}$ Marx, K. El Capital: crítica de la economía politica. Siglo XXI de España Editores, Madrid, 2010 (1873), libro primero, vol. I, p. 89.

${ }^{9}$ Véase para una explicación más detallada Postone, M. Time, labor and social domination. A reinterpretation of Marx's critical theory. Cambridge University Press, New York, 2003 (1993), pp. 158-159.

${ }^{10}$ Marx, K. op. cit., libro primero, vol. I, p. 88.

11 Nietzsche, F. Sobre verdad y mentira en sentido extramoral. Tecnos, Madrid, 1996 (1873), pp. 20-22. 
Nietzsche como fruto del lenguaje y no siendo más que «una suma de relaciones humanas» ${ }^{12}$ que se ha olvidado que lo son. Especial hincapié pone también Nietzsche en revelar el carácter histórico de los valores morales y las verdades en su obra La genealogía de la moral, en la cual pretende relativizar esos valores mostrando su origen -esto es, su historia-, y mostrando, así, el presente -al igual que hace Marxcomo resultado de un proceso histórico no necesario.

Sintetizando, tres son los elementos comunes entre las críticas de Marx y Nietzsche a tener en cuenta: por una parte, ambos autores señalan la situación de cosificación en la que el ser humano se encuentra y tratan de revelar el carácter social oculto de aquello que se presenta a este como naturalizado y ajeno a su praxis; en relación con esto, ambos insisten en la situación de dominación que este fenómeno supone, pues el ser humano vive sometido y manejado por sus propios productos sociales; por último, el tercer elemento que comparten es la importancia que otorgan a la abstracción en esos procesos fetichistas y de cosificación que describen.

\section{LA REALIDAD COMO LENGUAJE}

Tal como Nietzsche reivindica el carácter lingüístico y humano de las «verdades», análogamente García Calvo insiste a lo largo de todos sus textos en la «esencia» lingüística, social y humana que la Realidad tiene. Dando, como Nietzsche, especial importancia al lenguaje y al funcionamiento de este, García Calvo afirma que a través del lenguaje es como el ser humano crea la Realidad. Esto es, según García Calvo, la Realidad está formada por las palabras con significado -o vocabulario semántico- de nuestras lenguas, vocabulario que nos permite hablar de cosas y que constituye nuestra visión del mundo: «El vocabulario semántico de una lengua no es otra cosa que la Realidad, la multitud o sistema de las cosas que se habla, la Realidad, evidentemente, para la tribu correspondiente a dicha lengua, su Weltanschaunng o visión del mundo» ${ }^{13}$. La cuestión es que esta Realidad -lingüística, humana, cultural, histórica- quiere confundirse cada vez más con eso que por debajo del lenguaje hay y sobre lo que el lenguaje se asienta, pues, paradójicamente, el mismo significado de Realidad -tal como lo usamos y entendemos- parece querer referirse a algo extralingüístico, a lo que realmente existe fuera de condicionamientos arbitrarios o humanos.

De esta manera, García Calvo parece estar oponiéndose -como precisamente hacen Marx y Nietzsche- al carácter objetivo, incuestionable y más allá de toda duda que las cosas o la Realidad -como suma de todas las cosas-adquieren en nuestro mundo. La Realidad, creada por el ser humano a través del lenguaje, de alguna manera se cristaliza, se cosifica, se enajena del ser humano y adquiere un carácter objetivo y natural. He ahí por lo cual García Calvo emprende su tarea crí-

12 Ibidem, p. 25.

13 García Calvo, A. De Dios. Lucina, Zamora, 1996, p. 233. 
tica contra la Realidad y por lo que me he atrevido a hablar de un "fetichismo de la Realidad».

Así las cosas, ¿qué es lo que García Calvo hace para desfundamentar el valor que otorgamos la Realidad? Poner en entredicho la incuestionabilidad de la Realidad mostrando su origen verdadero, esto es, mostrando que, lejos de ser algo externo al ser humano, esta es más bien hija del lenguaje. Dicho esto, ¿cómo se crea, entonces, la Realidad?

En primer lugar, García Calvo vuelve a poner en juego un concepto que está ya en boca tanto de Marx como de Nietzsche: la abstracción ${ }^{14}$. Es a través de esta abstracción o de la «ley de la abstracción» -como también la llama-como «las funciones o relaciones de las cosas se solidifican, por así decir, o se materializan, convirtiéndose en cosa completa $»^{15}$. Esto es, a través de la abstracción se olvidan, como dice Nietzsche, las diferencias individuales, el mundo procesual y relacional, y se crean las ideas y conceptos que vienen a crear las cosas reales y el mundo ordenado y estructurado que llamamos 'realidad'. Este es el truco que el lenguaje ofrece y que García Calvo expone de esta manera:

La maravilla de la abstracción: a saber, que cosas que se producen diferentes son la misma cosa: que las maneras infinitamente variantes con que se pronuncia pato son todas pronunciaciones de la misma palabra (ideal) 'pato', gracias a lo cual, por diversos que los patos sean que uno se encuentre nadando en el estanque o cruzando en bandada por el cielo, todos son sin embargo 'pato', o sea que todos son lo mismo ${ }^{16}$.

Con el lenguaje, tal como Nietzsche explicaba, transformamos esa naturaleza en devenir en un mundo lleno de clasificaciones, orden, unidad y conceptos. A través de la abstracción olvidamos las diferencias individuales entre los objetos, pero, además, transformamos ese mundo en constante cambio y realización en un mundo estanco de conceptos e ideas. Y es que para poder referirnos a algo, tiene que saberse sin lugar a dudas qué es aquello a lo que nos estamos refiriendo. Es decir, al hablar y nombrar la palabra 'pato', no puede haber duda de qué es un pato y de su definición. Así quedan los patos encerrados dentro de una definición fija, inmutable, y queda aquello que por debajo del lenguaje hay convertido en un concepto al que, en verdad, nada puede pasarle ni puede este cambiar de ninguna manera. La

${ }^{14}$ En la teoría marxiana es a través de la abstracción como se igualan las mercancías y, a su vez, los trabajos humanos. Respecto a la abstracción de los trabajos, así se expresa Marx en El Capital: "La igualdad de trabajos toto calo [totalmente] solo puede consistir en una abstracción de su desigualdad real, en la reducción al carácter común que poseen en cuanto gasto de fuerza humana de trabajo, trabajo abstractamente humano». MarX, K. op. cit., libro primero, vol. I, p. 90. En Nietzsche, análogamente, es la abstracción la que permite olvidar las diferencias individuales, crear los conceptos e igualar las diferentes cosas y experiencias humanas, pues «todo concepto se forma por equiparación de casos no iguales». Nietzsche, F. op. cit., 1996, p. 23.

${ }^{15}$ García Calvo, A. Lalia. Ensayos de estudio lingüistico de la Sociedad. Siglo XXI de España Editores, Madrid, 1973, p. 243.

16 García Calvo, A. Avisos para el derrumbe. Lucina, Zamora, 1998, p. 44. 
cuestión está en que esa existencia tiene un "precio», es decir, que las cosas no siguen siendo iguales al convertirse en reales, que de alguna manera cambian cuando nos referimos a ellas a través del lenguaje.

En el fondo, la misma crítica al pensamiento metafísico y a su concepción del mundo como algo cosificado, objetivo, terminado, fijo, estable y estructurado es la que recorre toda la obra de Agustín García Calvo. Tal como Nietzsche ${ }^{17}$ ataca a todo lo que cierra la experiencia al mundo en devenir, en proceso, en relación y cambiante, así denuncia también García Calvo el olvido al que nos vemos sometidos al tomar la Realidad (estructurada, total, fija, creada con cosas y conceptos inmutables) como lo único que hay. Cuestión que nos acerca al corazón del pensamiento del zamorano, el cual establece una distinción y oposición entre dos mundos enfrentados que constituye la base filosófica sobre la que va a desarrollar sus trabajos -lingüísticos como políticos, etc.-. Esta distinción central en todo su pensamiento, por cierto, García Calvo parece recogerla de un "pensador prefilosófico» ${ }^{18}$ : Heráclito.

Es el propio García Calvo, a este respecto, el que traduce los fragmentos de Heráclito que aquí voy a citar, dejándonos una consistente traducción, ordenación y edición crítica de los fragmentos del libro heraclitano. Hecho que, por cierto, evidencia que García Calvo es gran estudioso y heredero, en algunos aspectos, del pensamiento de Heráclito. Como ejemplo se podría poner el fragmento más famoso que del libro del presocrático nos ha llegado: «En unos mismos ríos entramos y no entramos, estamos y no estamos» ${ }^{19}$. Si bien este fragmento ha sido muchas veces citado para exponer la doctrina de Heráclito de la constante fluidez (pánta rheî) de la phýsis ${ }^{20}$, esta idea no nos estaría más que presentando la mitad de lo que el fragmento nos quiere expresar, que no es otra cosa que la contradicción en la que se asienta la

${ }^{17}$ Existen ciertos elementos en común que permiten hablar de una similar crítica al pensamiento metafísico en Marx y Nietzsche, de lo que se puede deducir que García Calvo confluye con ambos en este aspecto de su análisis, y no solamente con Nietzsche. Como breve ejemplo-pues desarrollar este aspecto excede la extensión de este artículo-, Nietzsche, después de comparar «la filosofía metafísica» con «la filosofía histórica», escribe que «el pecado original de todos los filósofos es su falta de sentido histórico». A lo que añade: «Todo ha devenido, no hay datos eternos, lo mismo que no hay verdades absolutas. Por eso de ahora en adelante es necesario el filosofar histórico». Nietzsche, F. Humano, demasiado humano. Akal, Madrid, 2001 (1878), vol. I, \$1-2, pp. 43-44. Con respecto al pensamiento marxista, dando igualmente importancia a la historización de los elementos cosificados, Engels escribe que, en contra de la filosofía metafísica que «se ocupaba de los objetos como algo hecho y fijo" y que "enfocaba los objetos como cosas fijas e inmutables», "la filosofía dialéctica acaba con todas las ideas de una verdad absoluta y definitiva y de un estado absoluto de la humanidad, congruente con aquélla. Ante esta filosofía, no existe nada definitivo, absoluto, consagrado; en todo pone de relieve lo que tiene de perecedero, y no deja en pie más que el proceso ininterrumpido del devenir y del perecer». Marx, K. y Engels, F. Obras escogidas. 2, Akal, Madrid, 1975, pp. 410, 382.

${ }^{18}$ García Calvo, A. Razón común. Edición crítica, ordenación, traducción y comentario de los restos del libro de Heraclito. Lucina, Zamora, 2006 (1985), p. 187.

19 Ibidem, p. 186.

${ }^{20}$ Véase a este respecto la comparación que hace García Calvo entre las diferentes maneras en que es citado este fragmento por autores clásicos, así como la justificación de la elección de la cita que él recoge de Heráclito Homérico descartando las demás. Ibidem, pp. 186-189. 
phýsis o-cometiendo un anacronismo- la Realidad. Y es que la clave se encuentra en la antítesis del fragmento: "Entramos y no entramos, estamos y no estamos».

Brevemente, este fragmento -siguiendo la interpretación de García Calvoviene a expresar que, por un lado, entramos en unos mismos ríos. Y es que si ayer me bañé en el río Ebro y hoy vuelvo a hacerlo, está claro que me he bañado en el mismo río: el Ebro. La idea -como abstracción e idealización que es- no cambia, permanece invariable y dentro de su definición. Pero, por el otro lado, el fragmento también nos muestra cómo en ese río se han estado produciendo cambios y nos damos cuenta, por ejemplo, de que no es la misma agua la que hoy me moja y la que me mojó ayer. El río Ebro o los ríos a los que Heráclito se refiere están en constante cambio y esa manera de ser es totalmente inasible e indefinible a través de ideas o palabras. Lo realmente importante está en el hecho de que esos dos mundos totalmente opuestos conviven en la Realidad. La Realidad, pues, es totalmente contradictoria ${ }^{21}$.

Pues bien, García Calvo recoge esta oposición entre dos mundos que Heráclito presenta para denunciar la cosificación ${ }^{22}$ y el «fetichismo» que el propio funcionamiento del lenguaje conlleva, así como, derivada de esto, la anulación y olvido que acontece de la dimensión en devenir, procesual, relacional, perecedera, cambiante e inasible que hay por debajo de las idealizaciones y abstracciones del lenguaje. Dos mundos conviven en total oposición, por un lado el mundo cosificado, terminado y dado que el pensamiento metafísico supone (y que tanto Marx como Nietzsche también critican; véase nota 17) y por el otro un mundo indefinido y desconocido, cambiante y perecedero que, por cierto, nos abre a la experiencia de la falsedad de la Realidad y a infinitas - por ser incontables- posibilidades de ser y vivir $^{23}$. Pues mientras la Realidad se presenta como la conjunción total en que todas las cosas e ideas reales o que existen se resumen en una sola cosa o idea ${ }^{24}$, por debajo de esta García Calvo distingue otra dimensión en devenir sobre la cual vienen las ideas a establecerse.

Pues lo interesante de todo esto que llamamos [...] realidad al modo contemporáneo consiste en su condición de ser una componenda (imposible en verdad, pero así real) de dos componentes incompatibles: uno la idea de la cosa, que es por su propia definición intemporal, eterna [...], esto es, idéntica consigo misma, y otro aquello que se supone por debajo de las ideas de las cosas, incapaz por tanto de ideación ${ }^{25}$.

${ }^{21}$ Ibidem, p. 188.

22 García Calvo utiliza explícitamente el término "cosificación» para referirse al proceso de abstracción que se lleva a cabo a través del lenguaje (y del dinero) en varias de sus obras, tal como en el libro Lalia, concretamente en su ensayo Cosas y palabras, palabras y cosas: «Y así podemos llegar a distinguir grados sucesivos de realidad abstractiva, definidos en general por el hecho de que los elementos de cada grado resultan de la cosificación de funciones o relaciones que rigen entre elementos del grado anterior». García Calvo, A. op. cit., 1973, pp. 243, 245.

${ }^{23}$ García Calvo, A. op. cit., 1996, p. 180.

${ }^{24}$ Ibidem, p. 56.

${ }^{25}$ García Calvo, A. op. cit., 2006, p. 188. 
De esta manera, parece que García Calvo recupera de algún modo la intuición nietzscheana de que lo verdadero es algo inaccesible a través del lenguaje, algo que se corrompe y olvida al establecer las "verdades» y realidad humanas con los mecanismos del lenguaje. Sin embargo, aunque se olvide la existencia de ese mundo en devenir, García Calvo insiste en la necesidad de que haya algo tal. Ese algo no es otra cosa que el campo pregramatical o mundo en que se habla -por contraposición al mundo de que se habla- y al que los índices deícticos ${ }^{26}$ se refieren ${ }^{27}$. Pues debe haber algo -como él dice, usando un cuantificador indefinido ${ }^{28}$ - sobre lo que las palabras e ideas se asientan. La contradicción entre este mundo pregramatical y el mundo ideal y lingüístico es expuesta en las obras dedicadas a la lingüística (como en su obra Del lenguaje, por ejemplo) como oposición entre mundo en que se habla y mundo de que se habla: «En suma, uno es el mundo en el que se habla y el otro el mundo de que se habla; y el uno no puede ser el otro ${ }^{29}$. La cuestión que aquí nos interesa es que el concepto e idea de Realidad viene a crearse para intentar referirse (de manera, paradójicamente, lingüística) a ese mundo no-ideal y «exterior a la operación lingüística $»^{30} \mathrm{y}$, de alguna manera, para intentar unir esos dos mundos antagónicos.

Creo que debo darnos a entender, primero, que con algún lugar o mundo hay que contar como campo pregramatical, sobre el cual actúe y se monte el sistema de la gramática; y segundo, que no puede valer para el caso la hipótesis de un mundo en general, sino que se impone la de dos distintos, a salvo de que luego lo que suelen llamar mundo real o realidad resulte ser una componenda o confusión entre los dos, como que pretende por un lado constar de cosas denominadas y por el otro estar aquí. Pero que, en suma y por lo pronto, lo que debería quedarnos claro es que una cosa es el mundo de la mostración, al que los índices deícticos, apuntando desde la producción lingüística, se refieren, y otra cosa el mundo de la significación, al que pretenden referirse, por su significado, las palabras que lo tengan ${ }^{31}$.

La Realidad, así, no solo se enajena del ser humano y aparece como algo independiente de este y de su lenguaje, sino que además se cosifica de tal manera que aparece como idea objetiva, eterna, natural y ahistórica y se separa del mundo -y del tiempo, que no es otro que ahora, este momento en el que aprieto esta tecla del teclado- en el cual vive y habla el ser humano -el mundo en que se habla-, pre-

${ }^{26}$ Los índices deícticos son palabras (como 'yo', 'ahora' o 'allí') que señalan a la situación comunicativa y que solo son entendibles en relación con el contexto del hablante. Por tanto, si interesan a García Calvo es porque estos índices deícticos no son palabras con significado que se refieran al mundo de la significación, sino que apuntan al mundo extralingüístico donde se lleva a cabo el acto comunicativo -esto es, al mundo en que se habla-.

${ }_{27}$ García Calvo, A. Del lenguaje. Lucina, Zamora, 1979, p. 340.

${ }^{28}$ Ibidem, pp. 345-346.

29 Ibidem, p. 342. Según Bonilla, García Calvo parece estar siguiendo aquí, al diferenciar entre los dos niveles del lenguaje, la teoría del lenguaje de Karl Buhler. Bonilla, J. op. cit., p. 90.

30 Ibidem, p. 341.

31 Idem. 
sentándose como una construcción ideal y atemporal ${ }^{32}$ sobre la que se puede hablar y se puede también estudiar, investigar científicamente, descubrir sus leyes y esencia natural, etc. Pues al establecerse un concepto ideal como es el de Realidad sobre el mundo cambiante y en devenir no puede esto más que contribuir a convertir cada vez más ese mundo indefinido en ideal y lingüístico. Esto es, contribuir a que el mundo en que se habla se convierta en el mundo de que se habla, que el mundo en devenir se convierta, simplemente, en las ideas y en las palabras a través de las cuales nos referimos a él, que el mundo en que se habla se convierta en cosas de la Reali$\operatorname{dad}^{33}$. "Cuando" verdaderamente, como dice Nietzsche, «no hay ninguna "cosa" ${ }^{34}$.

De este modo, García Calvo explica a través de la exposición de un proceso histórico cómo sobre este mundo en que se habla se han ido creando nociones tan aparentemente reales como la de 'agente', 'tiempo', 'espacio', 'cosa', y cómo se ha ido creando esa Realidad a través del uso del lenguaje que se ha venido haciendo ${ }^{35}$. Podríamos decir que tal como Nietzsche relativiza nociones como las de 'sujeto' y 'cosa', asimismo García Calvo las relativiza y las sitúa en un proceso histórico dirigido - por decirlo de alguna manera- por el propio funcionamiento y uso que se ha venido haciendo del lenguaje. A este respecto sí cabría decir que García Calvo da una explicación meramente lingüística e histórica a un proceso que Nietzsche sitúa en el ámbito, además de histórico, biológico-evolutivo. Esto es, en García Calvo es el propio desarrollo que han tenido la sociedad y el lenguaje el que ha creado las nociones de 'cosa', 'agente', 'tiempo', 'espacio', 'realidad' y demás, no necesariamente -deduzco- presentes biológica y evolutivamente en el ser humano. Aun así, el rasgo común que une a estos dos autores -y que también los une con Marx, por ciertoes el hecho de dar una explicación histórica del mundo en el que vivimos, nos relacionamos, hablamos, así como el dar importancia -frente a las ideas y categorías metafísicas, aparentemente naturales y eternas, como las postuladas por Kant ${ }^{36}$

32 García Calvo explica en su obra Contra el Tiempo que «lo real, una cosa, para ser la que sea y ocupar el lugar que ocupe, tiene que, en un momento dado, anular el tiempo verdadero, renunciar a la continuidad o infinitud». García Calvo, A. Contra el Tiempo. Lucina, Zamora, 2001 (1993), pp. 18-19. Esto es, para que algo se cosifique y pase a convertirse en cosa de la Realidad tiene que convertirse en una construcción ideal y verdaderamente atemporal. Digo verdaderamente atemporal porque García Calvo distingue entre lo que era de verdad el tiempo, esto es, algo inasible e infinito que sentimos que pasa, y el Tiempo ideado y espacializado que se puede medir, contar y en el que suponemos diferentes puntos (ayer, hoy, el presente, pasado mañana, etc.). Así, una construcción ideal, como una idealización geométrica, tiene que anular el tiempo verdadero y su carácter de devenir, pues su definición conlleva la necesidad de tener que ser vista o concebida toda de una vez.

33 García Calvo, A. op. cit., 1973, p. 169.

${ }_{34}$ Nietzsche, F. op. cit., 2001, vol. I, $\$ 19$, p. 54.

35 Desarrollar el proceso histórico-lingüístico que García Calvo expone sería demasiado largo para este artículo. Aun así, puede consultarse esto en la obra Del lenguaje, especialmente en el último capítulo. García Calvo, A. op. cit., 1979, pp. 393-436.

${ }^{36}$ García Calvo parece compartir con Nietzsche el propósito de historizar las categorías -como las kantianas- supuestamente ontológicas. Nietzsche, en este sentido, denuncia que el ser humano convierte en categorías ontológicas aquellas categorías, como el sujeto, que no eran más que meras categorías gramaticales. Así, si de alguna manera parece que existen agentes y sujetos, esto se 
a los procesos históricos que han dado lugar al presente. Dicho esto, no me gustaría terminar este capítulo sin hacer mención a un ensayo titulado Sobre la realidad, o de las dificultades de ser ateo, incluido en la obra Lalia y en el cual, como si de la genealogía nietzscheana se tratase, García Calvo hace una reconstrucción histórica y etimológica del origen y desarrollo del término 'realidad'. Lo que parece indicarnos, por cierto, que García Calvo parece haberse dado cuenta de la importancia que tiene el relativizar históricamente lo que aparece como eterno y cosificado, tarea que los tres autores tratados en este artículo llevan a cabo.

Pues bien, brevemente, García Calvo expone en el ensayo mencionado que el término 'realidad' y su significado están lejos de ser algo eterno, objetivo y externo al ser humano -tal como se los supone-. Y es que, por mucho que la Realidad parezca ser algo muy presente en nuestros días, algo muy en boca de todo el mundo, García Calvo advierte:

Al mismo tiempo comprobamos que la Realidad es relativamente reciente y moderna, por así decir; pues no encontramos más que algunas trazas y gérmenes suyos en el mundo antiguo (bien apurado se vería el que tratara de traducir al griego antiguo la palabra realidad), y es imposible, a lo que creo, encontrar nada que sea equivalente en otras lenguas y culturas extrañas a nuestro mundo ${ }^{37}$.

Así, después de definir la Realidad como un producto exclusivo de nuestro tiempo y cultura (quitándole así toda pretensión de universalidad y objetividad), pasa el zamorano a exponer el origen etimológico de la Realidad, reparando en un primer momento en una antítesis del griego antiguo que va a resultar ser fundamental para el estudio etimológico: la antítesis $\lambda \dot{o} \gamma \omega / \tilde{p} p \gamma \omega$. Pues esta antítesis contrapone lo que es solo de palabra o en apariencia $(\lambda \dot{o} \gamma \omega)$ a lo que es de veras y está por debajo de las palabras y las razones (है $\beta \gamma(\omega)$. La cuestión está, tal como denuncia García Calvo, en que «se desconoce desgraciadamente que el segundo miembro no por contraponerse al primero deja de ser palabras y razones también él mismo» ${ }^{38}$; esto es, que el que dice que algo es de veras no por ello deja de hablar o de emitir

debe «a la seducción del lenguaje (y de los errores radicales de la razón petrificados en el lenguaje), el cual entiende y mal entiende que todo hacer está condicionado por un agente, por un "sujeto"». Nietzsche, F. La genealogía de la moral, Alianza, Madrid, 2011 (1887), «Tratado primero", \$13, p. 67. Resulta interesante que Marx, por su parte, trata asimismo de historizar las categorías de la economía burguesa. Marx, K. op. cit., libro primero, vol. I, p. 93. No obstante, ciertos autores, como el economista marxista Alfred Sohn Rethel, han tratado de llevar esa crítica también a las categorías del pensamiento, tratando de derivar el sujeto trascendental kantiano de la forma del valor y buscando el origen histórico de estas categorías supuestamente ontológicas. JAPPE, A. Las aventuras de la mercancía, Pepitas de calabaza ed., Logroño, 2016, nota 108, p. 273. Asimismo afirma Jappe, usando como referencia la crítica marxiana, que «el valor [...] es una forma "a priori" en el sentido kantiano». Ibidem, p. 144. Esta historización de las categorías sería, así, otro hilo conductor a través del cual unir a los tres autores tratados en este artículo, tema que deberá ser desarrollado en otro escrito por extensión.

37 García Calvo, A. op. cit., 1973, p. 159.

38 Ibidem, p. 160. 
un discurso. De este modo, una frase dicha para declarar -digamos- que alguien denuncia una injusticia solo de palabra, mientras que de hecho no hace nada ni trabaja para evitarla, no por ello deja de ser una expresión lingüística ella misma; no hace, así, nada ni trabaja tampoco el hablante que manifiesta esa situación, si no es solo de palabra $(\lambda \dot{o} \gamma \omega)$. Así, García Calvo afirma que esta antítesis estructura todo nuestro mundo y que el término 'realidad' se creó para traducir el segundo miembro de esta:

Pues me parece ver que el Ablativo latino rē de la palabra rēs, a veces reforzado con el adjetivo uērā, en la forma rēuērā (algo como 'en el hecho de veras', 'verdaderamente de hecho'), no fue otra cosa sino la traducción del elemento ěp $\gamma \omega$ del segundo miembro de la antítesis ${ }^{39}$.

Así las cosas, García Calvo parece tomar relevo a Nietzsche en la tarea de buscar el origen etimológico de conceptos tomados como naturales en nuestros días para desfundamentarlos y quitarles su apariencia objetiva. Y es que, tal como Nietzsche encuentra el origen de algunos de nuestros valores morales en ámbitos más bien económicos o materiales ${ }^{40}$, así también García Calvo encuentra que el significado de 'rēs' como el de 'है $p \gamma \omega$ ' parecían en un primer momento referirse a instituciones como el Trabajo, el Comercio o la Justicia, y que solo secundariamente se han venido a aplicar sobre las cosas llamadas naturales. Por lo cual se puede deducir que la Realidad ha tenido un origen bien humano, industrioso y comercial ${ }^{41}$.

Por lo demás, lo que García Calvo encuentra es que el realismo ha pasado a ser la ideología actual, así como el adjetivo 'realista' se ha convertido en una especie de sinónimo de 'bueno' ${ }^{\text {'2 }}$. Pues muchas veces vemos cómo se exaltan las cualidades de alguien o algo atribuyéndole el adjetivo de 'realista', 'práctico' o 'pragmático', que vienen a querer referirse a que, lejos de idealismos o ideologías, lleva a cabo las medidas «adecuadas», en el caso de un político, o realiza las gestiones «adecuadas», en el caso de un hombre de negocios ${ }^{43}$. Lo curioso del tema es precisamente que el realismo, siendo una ideología o doctrina que pretende decir cosas sobre el mundo,

39 Ibidem, p. 162

${ }^{40}$ Véase, por ejemplo, el origen del término 'culpa' (Schuld, en alemán), surgido del concepto 'tener deudas' (Schulden), que Nietzsche menciona. Nietzsche, F. op. cit., 2011, «Tratado segundo", $\$ 4$, p. 91.

${ }^{41}$ García Calvo, A. op. cit., 1973, pp. 163-164.

${ }^{42}$ Ibidem, p. 166.

${ }^{43}$ Valga como ejemplo la necesidad que encontraba el presidente del BBVA de llevar a cabo, para reducir el paro, "políticas realistas». EUROPA PRESS, "González (BBVA) ve posible un paro menor al 10\% con "políticas realistas"», Europa Press, 2016, 11 de marzo. Recuperado de https://www. europapress.es/economia/finanzas-00340/noticia-gonzalez-bbva-ve-posible-paro-menor-10-2020-politicas-realistas-20160311122335.html. Resulta interesante fijarse en cómo este aplica el adjetivo 'realista' con connotaciones positivas a las propias medidas políticas. En el fondo está la idea de que la política debe estudiar la Realidad y ajustarse a sus leyes -externas estas, por supuesto, al ser humano en forma de Realidad fetichizada-. 
intenta negar el carácter ideológico que tiene al querer mostrarse como lo que es de

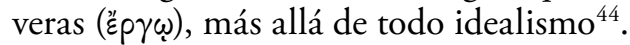

Ese realismo y esa Realidad del discurso político -aparentemente despolitizado- pretenden apoyarse sobre la objetividad de las leyes naturales o leyes físicas, las cuales les sirven de alguna manera de sustento - pues la Realidad histórica, social y moral parece apoyarse y justificarse sobre la Realidad física y, más aún, ser el reflejo de esta ${ }^{45}$ - . No obstante, García Calvo afirma que, históricamente, en primer lugar se crean las instituciones y las leyes, y que solo sobre estas se crean las especulaciones científicas y las leyes naturales. Hecho que está en relación con el origen de las cosas que antes mencionábamos y que venía a decir que «las cosas son primero asuntos, haciendas o negocios, antes de ser inocentemente cosas» ${ }^{46}$. A lo que el zamorano se pregunta:

¿Qué podrá, desde este momento, devolvernos la confianza en la verdad e independencia de las cosas naturales? ¿Quién va a quitarnos la sospecha de que sean estas cosas naturales, engendradas de algún modo por la praxis histórica y humana, servidoras suyas y factores sociales igualmente? ${ }^{47}$.

En definitiva, sintetizando, se podría decir que García Calvo intenta exponer el origen y desarrollo histórico de la Realidad para mostrar que esta tiene un nacimiento totalmente humano y ligado a la actividad humana. Esta Realidad se crea a través de un proceso lingüístico -tal como se explica en la obra Del lenguaje-, social e histórico y, por tanto, está lejos de ser algo objetivo, natural o incuestionable, siendo más bien un producto -como diría Marx en relación con la mercancíafruto de unas relaciones sociales históricamente determinadas.

Esto, por cierto, deslegitima toda apelación a la ciega necesidad de la Realidad y convierte al realismo en un discurso meramente ideológico -tomando el sentido marxista de ideología- que sirve como justificación y legitimación de un mundo que es en verdad histórico, social e ideal. Esta crítica a la Realidad permite también defenderse frente a todo discurso político que -tratando de negar su carácter político- quiere basarse en la Realidad de las leyes económicas que se imponen al ser humano como algo externo a él. Hemos visto cómo la Realidad no es más que lingüística -creada por las palabras semánticas de nuestras lenguas- y cómo esta se crea intentando anular el mundo en devenir, relacional y procesual que hay por debajo de las idealizaciones y abstracciones del lenguaje. Además, el propio término de Realidad no es más que un resultado de un proceso histórico bien humano.

Las consecuencias políticas que se pueden sacar de las investigaciones sobre la Realidad que García Calvo efectúa, por cierto, nos llevan a sospechar de todo discurso que se base en apelaciones a la naturaleza o a sus leyes para llevar a cabo

\footnotetext{
44 García Calvo, A. op. cit., 1973, p. 168.

45 Ibidem, p. 177.

46 Ibidem, p. 178.

47 Ibidem, pp. 178-179.
} 
medidas bien políticas e ideológicas. La Realidad está formada por palabras e ideas y, por tanto, no cabe pensar en una Realidad no-ideológica y natural o en una situación de «fin de las ideologías». Por lo demás, la crítica de García Calvo también nos protege frente a apelaciones a la objetividad de la lógica mercantil y económica que se le aparece al ser humano como si de algo externo a él se tratase (algo que Marx analiza en profundidad), así como, relacionado con esto, nos hace ver la falsedad de una situación en la que la Política va dejando aparentemente espacio a la Economía, la Técnica y a la simple gestión de la Realidad mercantil -siguiendo, claro, a las leyes «objetivas» del Mercado-. Y es que esa Realidad económica o natural, por mucho que se le aparezca al ser humano de manera fetichizada - esto es, siendo algo exterior a la praxis humana, algo con una lógica propia que se impone con ciega necesidad-, García Calvo recuerda que no es más que un producto de un proceso humano, lingüístico, social e histórico.

Cuando algunos de los ejecutivos de Dios más descarados proclamaban ya hace unos años «el final de las ideologías», y que ya no hay en realidad Política ni Partidos, sino solo Técnica y Economía, confesaban por un lado algo de la verdad, pero más insistían en la mentira por el otro, al creer y hacer creer que eso de la Economía (con Tecnología y su Padre que los parió a todos) no es, en cambio, cosa de ideas, sino algo así, vamos, como la Realidad.

Pero esta Realidad está hecha de ideas; esa Economía es en verdad Política: es la Política del Dominio que nos toca ${ }^{48}$.

En fin, si bien la Realidad se le aparece al ser humano como siendo algo objetivo, natural, eterno, cosificado, algo que se impone con exterioridad, y si bien vemos que la aceptación por la sociedad de esa Realidad y el realismo se impone casi como una necesidad natural a los seres humanos, lo que García Calvo se pregunta es lo siguiente: « No tenemos más bien todas las razones para pensar que se ha tratado de un proceso histórico, lingüístico y humano?» ${ }^{49}$.

\section{LA REALIDAD COMO DINERO}

Hemos visto hasta ahora, de la mano de García Calvo, cómo la Realidad está creada por el vocabulario semántico -esto es, por las palabras con significado de nuestras lenguas, tales como 'pato', 'casa' o 'verde'-, cómo la Realidad es una producción lingüística y de qué modo juegan los mecanismos del lenguaje como la abstracción - en la creación de esta. Pues bien, además de esta naturaleza lingüística, García Calvo analiza otra faceta de la Realidad que lo acerca al pensamiento de Marx. Y es que la Realidad, además de estar constituida por el vocabulario semántico de nuestras lenguas y ser, en fin, lingüística, está también formada

48 García Calvo, A. op. cit., 1998, pp. 19-20.
49 García Calvo, A. op. cit., 1973, p. 177. 
por el Dinero. Esto es, que las cosas son más reales cuanto más se habla de ellas ${ }^{50}$, pero que, al mismo tiempo, el curso de la historia ha hecho que las cosas sean también más reales cuanto más se cambian estas por Dinero ${ }^{51}$.

Según García Calvo, después de que el ser humano, a través de la abstracción, hubiera igualado y homogeneizado la naturaleza, una nueva abstracción se da cuando se introduce el Dinero. La cuestión ya no es que sean iguales los patos que uno se encuentra nadando en el río y los que volando cruzan el cielo al ser todos, no obstante, 'pato', sino que con el Dinero los patos son asimismo abstraídos y convertidos en números y en cómputos para el intercambio, convertidos en mercancías e igualados al resto de cosas de la realidad -todas ya mercancía, todas ya número y Dinero-. Así, un pato es igual a dos gallinas e igual a 10 kilos de trigo. En una operación de abstracción e idealidad más alta que con el lenguaje, las cosas van dejando de ser lo que eran, van desapareciendo para convertirse en una excusa para el intercambio. Todas las cosas son ahora homogeneizadas y traducidas a unidad monetaria sin poder evitar, sin embargo, y tal como con el lenguaje pasaba, que las cosas dejen de ser lo que eran. Se convierte así el Dinero en el nominador común y en el nombre común de todo objeto. Van las cosas desapareciendo para convertirse en simple Dinero, el ser más real de todos en el que el resto de cosas se deshacen, el nuevo Dios al que nuestra sociedad rinde culto ${ }^{52}$.

50 García Calvo no solo afirma que las cosas son reales porque se habla de ellas, sino que, además, insiste en que «en esto de la realidad hay grados» y que, así, las cosas son más reales cuanto más se habla de ellas. García Calvo, A. op. cit., 1996, pp. 49-50. Esta afirmación de los grados de la Realidad, que bien puede extrañar al que se acerca por primera vez al pensamiento de García Calvo, es coherente con la concepción que el autor tiene de esta. Pues si por Realidad entendemos que se refiere a la visión del mundo correspondiente a cada comunidad lingüística, de esto se deduce que lo real está lejos de ser algo objetivo y totalmente antagónico a lo no-real (tal como el pensamiento metafísico supone), sino que es el resultado de un proceso abierto en el cual las palabras del vocabulario semántico -o palabras con significado- de nuestras lenguas van sucediéndose, apareciendo unas y desapareciendo otras, definiéndose o desdibujándose en cada acto de habla. Este carácter procesual y abierto de la lengua aparece expuesto en De la construcción (Del lenguaje II), donde García Calvo escribe que «el sector del léxico semántico está abierto y no finito» y que «ahí está el sitio por donde el estado de la lengua se muestra imperfecto como estado, ya que cada acto de habla, aparte de la función directa que con su sentido ejerza sobre el ambiente, ejerce de rebote una acción sobre el sistema, por la que resulta alterado un tanto su sector semántico, si no es con la creación de una palabra, con la alteración de los límites y mutua ordenación de las palabras de tal sector"; GARcía Calvo, A. De la construcción (Del lenguaje II), Lucina, Zamora, 1983, pp. 400-401. En definitiva, el sector de las palabras con significado de nuestras lenguas (que constituye su Realidad) es infinito y cambia en cada acto de habla, por lo que la Realidad aparece como algo cambiante y en ella diferentes conceptos o ideas van adquiriendo o perdiendo Realidad. Así, que las cosas sean más reales cuanto más se habla de ellas se debe a que esas cosas muy mencionadas están muy presentes en la visión del mundo de la comunidad lingüística correspondiente, ya que «el mucho uso contribuye a redondear y definir, nunca del todo, la palabra» y, por tanto, la Realidad de la cosa definida a través de esa palabra. García Calvo, A. op. cit., 1996, p. 55.

51 García Calvo, A. op. cit., 1996, p. 52.

52 García Calvo, A. op. cit., 1998, pp. 44-46. 
Como vemos, lo que García Calvo afirma es que, de alguna manera, «el proceso económico no ha hecho más que copiar el proceso lingüístico ${ }^{53}$ y que

una vez que desde el comienzo está establecida esta intercambiabilidad entre la idea y las cosas, de tal forma que la idea puede valer por las cosas infinitas, y las cosas infinitas, a su vez, convertirse en ideales, en meros representantes de la idea, está ya en marcha de alguna manera, al menos en potencia, el proceso económico donde el dinero ocupa el lugar del significado, de la idea ${ }^{54}$.

Así, parece que la clave para entender la intercambiabilidad entre las cosas y la reducción de las cosas a Dinero está en la abstracción de sus diferencias que se lleva a cabo; abstracción, por cierto, que Marx también analiza ${ }^{55}$. Y es que, tal como el análisis de Marx descubre, tanto los trabajos humanos como los objetos aparecen igualados y homogeneizados entre ellos al convertirse en mercancías ${ }^{56}$. Es el hecho de que se producen mercancías (esto es, productos dirigidos desde el primer momento a ser intercambiados) lo que genera que los productos adquieran valor y que estos puedan intercambiarse entre ellos. Así también, es requisito indispensable para que las mercancías puedan tener su expresión dineraria que tengan en común el hecho de tener valor. Expresión dineraria que elimina las diferencias entre los valores de uso $-\mathrm{o}$ utilidad real- de sus productos y sus orígenes ${ }^{57}$.

Pues bien, según García Calvo, en este grado de idealidad que se da después de haberse dado el del lenguaje, dejan de importar las diferencias individuales entre las cosas, pero, además -introduciendo la terminología marxista en la interpretación de García Calvo-, deja incluso de importar el valor de uso que las cosas tienen desde que el trabajo abstracto, que busca el simple intercambio de objetos, toma relevancia en el capitalismo. La utilidad que los objetos puedan tener (e incluso el placer que puede uno encontrar en su uso o disfrute) pasa a un segundo plano al importar solo el valor. El diagnóstico que hace García Calvo es análogo en ciertos aspectos al efectuado por Marx, pues aquel ve también que las cosas se producen «para venderlas» y que el proceso de compraventa sustituye de algún modo a los antiguos usos y disfrutes que los objetos tenían ${ }^{58}$. Sí es cierto, cabe mencionar, que García Calvo no introduce términos como los de trabajo abstracto o valor de uso y valor -intro-

53 García Calvo, A. «Qué comprar, qué vender», Política y Sociedad, 1994, núm. 16, p. 14.

${ }^{54}$ Idem.

55 El propio García Calvo repara en este aspecto del pensamiento de Marx en una obra -publicada de manera anónima- que nos revela que el zamorano leyó y estudió la obra marxiana: «El análisis de Marx mostraba eximiamente en el Dinero la reducción a abstracción de todas las realidades». Anónimo, Apotegmas sobre el marxismo, La banda de Moebius, Madrid, 1979 (1977), p. 19.

56 Tal como dice Marx en El Capital, los seres humanos, «al equiparar entre si en el cambio como valores sus productos heterogéneos, equiparan recíprocamente sus diversos trabajos como trabajo humano». Marx, K. op. cit., libro primero, vol. I, p. 90.

57 «El dinero es precisamente la forma en la cual está extinguida la diferencia de las mercancías en cuanto valores de uso, y por ende también la diferencia de los capitales industriales consistentes en estas mercancías y en sus condiciones de producción». Ibidem, libro tercero, volumen viI, 502.

58 García Calvo, A. op. cit., 1994, p. 14. 
ducidos aquí por mí para interpretar su obra a través de Marx-. En lo que García Calvo insiste explícitamente es en que la necesidad, el uso, la utilidad y el disfrute que los objetos podían satisfacer han quedado casi completamente fuera del proceso de producción y de compraventa $a^{59}$, además de en que "cualesquiera productos son producidos ya como mercancías» y en que «se produce para vender y comprar, y [...] ahí se agota el fin del proceso de producción ${ }^{60}$. Sin hacer un análisis tan exhaustivo como hace Marx respecto al trabajo abstracto y sus características (como la sociabilidad indirecta, por dar el ejemplo más claro), sí parece que García Calvo repara en la característica principal que el trabajo humano adquiere en el capitalismo como mero productor de mercancías destinadas al intercambio.

Así pues, de esta mercantilización del mundo en que vivimos y de esta conversión de las cosas en Dinero se desprende que lo importante en este contexto, así, no es el placer o utilidad que podamos sacar de los objetos que producimos, sino el intercambio y la reproducción -este término lo introduzco yo- del proceso mismo de producción y compraventa, esto es, «la cosificación y el reemplazamiento de las cosas por el proceso" ${ }^{61}$. Poco importa ya que los coches que se producen sirvan de veras al ser humano para desplazarse de manera eficiente y racional (o que hubiera maneras más racionales y éticas de transporte), o que estén los cepillos de dientes con música (que existen y se pueden comprar en conocidas tiendas online) satisfaciendo una necesidad real de la sociedad, sino que lo verdaderamente esencial es seguir produciendo y vendiendo productos, seguir produciendo, comprando y vendiendo -aunque aparentemente cosas-, en el fondo, Dinero. Pues si el Dinero se había creado en un principio como medio para adquirir cosas, una vez que las cosas se han convertido en Dinero, poca esperanza hay de que esa reconversión del Dinero en cosa se efectúe ${ }^{62}$. Más bien parece que el Dinero es lo que se convierte en cosa, adquiere aparentemente materialidad y se transforma en la realidad palpable de nuestras vidas ${ }^{63}$.

El objetivo de nuestras vidas se centra, pues, en la adquisición de Dinero y en la reproducción del proceso productivo y de compraventa. Este proceso «viene a ocupar un lugar como cosa" y de alguna manera viene a sustituir a la vida, pues pasa la vida a centrarse en la repetición de ese proceso ${ }^{64}$. El proceso se convierte en nuestra vida, en nuestra Realidad. No hay más Realidad que esta que la Economía (no esta economía histórico-socialmente determinada, no, sino la Economía aparentemente «objetiva» y fetichizada) impone, no hay cosa más real que el Dinero, ni actitud más realista que adaptarse a las reglas de juego del Mercado, que someterse al Trabajo (así, sin determinaciones histórico-sociales de nuevo) y adquirir Dinero.

\footnotetext{
59 Ibidem, p. 9.

60 Ibidem, p. 14.

61 Ibidem, p. 15.

62 Ibidem, p. 11.

63 Ibidem, p. 12

64 Ibidem, p. 14.
} 
Aunque con aspectos enfrentados y expresado en términos diferentes, parece que García Calvo coincide con la interpretación que hace Marx de que en el capitalismo, como Moishe Postone afirma claramente, se trata de producir por produ$\operatorname{cir}^{65}$ y de que lo que importa, en verdad, lejos de la utilidad de los productos, es la reproducción del proceso productivo y la extracción de plusvalor -en García Calvo la adquisición de Dinero-. Si bien, en el análisis marxiano, son las propias condiciones de producción (en el fondo relaciones sociales) constituidas por el trabajo abstracto las que imponen el proceso de producción e intercambio de mercancías ${ }^{66}$, es cierto que no puede hallarse un análisis tan exhaustivo de las relaciones básicas del capitalismo en la obra de García Calvo, quien se centra en analizar las consecuencias del propio proceso, las similitudes entre el proceso económico y el lingüístico y en atacar a la fe que el sistema necesita para reproducirse: fe en el dinero y en que este tiene poder de compra real, fe en el crédito, fe en el Crecimiento, fe en el Futuro, fe, en fin, en los ideales del Poder.

Así y todo, una crítica fundamental que une a ambos autores es la reivindicación del carácter social oculto que ese Dinero tiene. Y es que la conversión de los objetos en Dinero es obra humana, así como el valor que las cosas tienen. No tienen los objetos valor en sí, sino que, en términos de García Calvo, esto solo se sostiene a través de la fe o, tal como él lo expresa, el Dinero -en su fase actual más abstracta en forma de crédito- solo se sostiene a través de la $\mathrm{fe}^{67}$. ¿Qué sería un billete sin la fe que la sociedad le otorga? Un simple papel. ¿Qué sería una moneda si no creyera la gente en que esta tiene realmente un valor? Un pedazo de metal. Así, como todos los ideales que sostienen la Realidad y el sistema en el que vivimos, necesita tam-

65 Postone, M. op. cit., p. 281.

${ }^{66}$ Ibidem, pp. 158-159.

${ }^{67}$ García Calvo, A. op. cit., 1996, p. 63. Esta afirmación de la necesidad de la fe para el sistema podría sugerirnos que García Calvo culpa a un fenómeno ideológico -que como ideología estaría impuesta, es de suponer, por el Poder o la clase dominante- del fetichismo y de la conversión de las cosas en dinero, mientras que el Marx maduro pretendería explicar el fetichismo al mismo tiempo no solo apelando a la conciencia de los sujetos, sino a unas determinadas condiciones de producción (en el fondo relaciones sociales) que se imponen a los sujetos con ciega necesidad y que generan ese tipo de conciencia. Kohan, N. Nuestro Marx, 2011, p. 355. Recuperado de http://www.rebelion.org/docs/98548.pdf. No obstante, es posible encontrar en las obras de García Calvo fragmentos en los cuales comparte con la teoría del fetichismo de Marx la afirmación de que este fenómeno no es algo impuesto por la clase dominante, sino fruto del proceso de cosificación y personificación que se da en el capitalismo -lo que no quita, siguiendo también a Marx, que este proceso no se acompañe de una adhesión subjetiva de sus partícipes, el cual se les presenta como ley natural y objetiva-, lo que acerca - con sus particularidades- aún más a los dos autores. En palabras de García Calvo «el verdadero dinero viene a ser el «sujeto». García Calvo, A. op. cit., 1994, p. 16. «Se necesita lo que el dinero quiere que se necesite». Comuna Antinacionalista Zamorana, Comunicado urgente contra el despilfarro, Pepitas de calabaza ed., Logroño, 2016 (1972), p. 61. «Era el hombre, bajo forma de obrero capitalista, el que venía a ocupar la función de cosa y mercancía para el Hombre del Capital, Hombre que era en realidad el propio Dinero, definitivamente personificado». Ibidem, p. 70. 
bién el Dinero de la fe de las poblaciones del mundo ${ }^{68}$. Fe que no puede ser más que social (solo el hecho de que todos creamos convierte a eso en Realidad), pero que se nos aparece como si fuera natural, como si las cosas realmente tuvieran el valor que se les otorga o como si el Dinero tuviera poder de compra.

Así, lo interesante para este artículo es que se puede decir, siguiendo a García Calvo, que el proceso económico que en este artículo se analiza guiados por las investigaciones de Marx es, de alguna manera, una continuación del proceso lingüístico que Nietzsche -y el propio García Calvo- describen. De lo que se puede concluir que el fetichismo de la mercancía es, en algunos aspectos, análogo al fetichismo del lenguaje. Aventurándonos en esta suposición, parece que lo que uniría, sintetizando, ambos procesos sería la abstracción de las diferencias que se llevan a cabo, así como la aparente objetividad y necesidad con que los "productos» histórico-sociales -verdades, valores, mercancías, dinero-se imponen a los sujetos. «Objetividad» y dominación que son, por cierto, resultado de la propia praxis histórica de los seres humanos, del desarrollo histórico del lenguaje, así como del desarrollo -histórico, igualmente- de las relaciones sociales que moldean el sistema capitalista. Podríamos, incluso - uniendo las críticas de Marx y Nietzsche-, afirmar que lo que García Calvo denuncia es una situación en la cual el ser humano pierde su carácter real de sujeto y en la cual lo abstracto domina lo concreto $^{69}$, resumiendo en un solo término esa abstracción como Realidad. Es por ello, precisamente, por lo que afirmo que se puede, leyendo a García Calvo a través de Marx y Nietzsche, interpretar que el zamorano analiza un fenómeno social que se puede definir como fetichismo de la Realidad, y bajo el cual recoge aspectos tanto del fetichismo del lenguaje y la verdad de Nietzsche como del fetichismo de la mercancía de Marx. Esta es una de las grandes aportaciones, ciertamente, que nos deja el pensamiento de García Calvo, y la cual he querido destacar en este artículo. No es, sin embargo, la única, pues nos ha dejado amplios y originales estudios lingüísticos y filológicos, interesantes de leer por sí mismos y -en relación con el tema de este artículo- de los que podemos concluir, entre otras cosas, los procesos de cosificación mencionados y, asimismo, las posibilidades que el propio lenguaje ofrece para escapar de esa Realidad con pretensión totalizadora. He aquí, como cierre del artículo, algunas ideas al respecto.

68 García Calvo, A. op. cit., 1996, pp. 62-63. Esta necesidad de la fe para el Dinero se hace aún más patente desde la pérdida del patrón oro y la implantación del dinero fiduciario, respecto al cual abiertamente se expresa que se basa en la fe o confianza de sus usuarios, ya que «el crédito no es otra cosa que una anticipación de las ganancias futuras previstas». JAPPE, A. Crédito a muerte, Pepitas de calabaza ed., Logroño, 2011, p. 113.

${ }^{69}$ Esta sería una de las características, por cierto, que Anselm Jappe, leyendo a Marx, destaca de la sociedad capitalista: «Uno de los rasgos distintivos de la sociedad capitalista fetichista es tener una naturaleza "conceptual": la abstracción, encarnada en el dinero, no deriva de lo concreto, sino que lo domina». JAPPE, A. op. cit., 2016, p. 149. 


\section{5. ¿ES LA REALIDAD TODO LO QUE HAY?}

Dice Marx que, por el fetichismo, los objetos terminan mandando sobre las personas. Esto es, al no estar la producción planificada de acuerdo a las necesidades reales de la sociedad, sino de acuerdo a intereses de mercado, la propia lógica del mercado arrastra a los capitalistas a situaciones irracionales y de crisis. El Mercado, las mercancías, aparecen personificados, aparecen rigiendo el valor de las cosas y la situación del mundo y de la economía. Desde esta visión fetichista, es el Mercado o los Mercados los que marcan el precio del pan, la subida del precio del pescado o la prima de riesgo de los países. Y nos creemos esto sin darnos cuenta de que ese Mercado, de que esas mercancías, de que ese valor de las cosas es fruto de la actividad humana, fruto de unas condiciones de producción y consumo concretas.

Asimismo, podríamos decir que la Realidad que García Calvo analiza aparece también dominando a las personas de manera irracional. Esa Realidad creada lingüísticamente y sustentada por la fe en ciertos ideales acaba por imponerse y por dominar a las poblaciones del mundo. Terminamos por creer que ciertamente la Realidad es así, que no hay más Realidad que esta que vivimos, que no podrían ser las cosas de otra manera. Esas palabras de nuestro vocabulario, esos ideales y ese Dinero acaban por convertirse en cosas reales y por imponernos un estado de cosas que aparece como ajeno a nosotros mismos. Acaban las cosas y el Dinero teniendo un valor en sí mismo realmente, termina la naturaleza teniendo esas leyes físicas que nosotros hemos introducido ahí y termina la Economía rigiéndose «objetivamente» según esas leyes que fueron creadas por el ser humano. Leyes, fe y Realidad, por cierto, que cabría dudar si son manejadas desde lo alto por una clase dominante o si, tal como Marx expresa, la clase social dominante no caería también bajo el fetichismo y bajo las mismas contradicciones ${ }^{70}$. Y es que García Calvo ya advierte que el dominio de la Realidad y de la fe alcanza hoy en día a toda la sociedad, que la fe en la Realidad y en los ideales dominantes es más fuerte incluso cuanto más alto se sube en la pirámide del Poder. Y que así, también los mandatarios aparecen sometidos a esa fe en la Realidad y a ese fetichismo que les hace pensar que la Realidad existe realmente como algo ajeno al ser humano, que efectivamente no hay Política, sino solo Técnica y Economía, y que la Economía no es cosa de ideas. Sin darse cuenta de que esa Realidad que nos venden es en verdad ideológica y que la Economía es en verdad Política ${ }^{71}$.

Es, por tanto, importante descubrir la esencia ideológica y fetichista que la Realidad tiene, revelarla como la ideología actual que sirve para el mantenimiento del orden establecido. Descubrir el fetichismo de la Realidad que existe en nuestra sociedad actual y darse cuenta de que, al ser la Realidad ideológica y social, las

70 Valga como ejemplo la reciente crisis económica del 2008, durante la cual «se tuvo más que nunca la impresión de que las "clases dominantes" no dominaban gran cosa, de que, bien al contrario, ellas mismas estaban dominadas por el "sujeto automático" (Marx) del capital». JAPpe, A. op. cit., 2011, p. 111.

${ }^{71}$ García Calvo, A. op. cit., 1998, p. 20. 
cosas podrían ser de otra manera o, como suele repetir el propio García Calvo, que la Realidad no es todo lo que hay. Pero, a este respecto, uno se puede preguntar ¿cómo superar este fetichismo de la Realidad que García Calvo denuncia? y, también, ¿qué utilización del lenguaje es la que genera el fetichismo?

Pues bien, según García Calvo, parece que todo lenguaje tiende a convertirse en Realidad y a "encerrar» las infinitas cosas, el mundo en devenir, abierto y procesual en definiciones cerradas e inmutables. Y es que hacerse una idea de algo (función fundamental en nuestro lenguaje) implica la abstracción y la conversión en cosa real de eso que por «debajo» del lenguaje hay-es decir, del mundo en devenir, indefinido, cambiante y extralingüístico o mundo en que se habla-. Aun así, García Calvo reivindica también el carácter emancipador que el lenguaje tiene, estando la clave en la infinitud del sector semántico ${ }^{72}$. Y es que, aunque la Realidad se le aparezca al ser humano como algo objetivo y terminado y el Poder reivindique la absolutidad y necesidad de esa Realidad, todo acto de habla influye en el sector semántico de la lengua y así, en la Realidad definida a través de ese sector semántico. Cada vez que hablamos estamos contribuyendo a definir, redefinir o desdibujar el significado de las palabras que utilizamos y, de rebote, el resto de las palabras cuya definición está relacionada y es dependiente de las primeras. Pues tampoco el lenguaje - con García Calvo- puede pensarse como algo estático y con definiciones aisladas, sino que cada palabra que enunciamos viene a influir en la definición de esta y el resto de las palabras de nuestro vocabulario. De lo que se deriva que cada vez que hablamos estamos influyendo de alguna manera sobre el vocabulario semántico de nuestra lengua y sobre la Realidad que se crea a través de este vocabulario ${ }^{73}$.

Así pues, la clave está también en que, según García Calvo, no existe nada como un vocabulario semántico común a todas las lenguas que pudiera pensarse como la Realidad en sí, sino que lo que tienen en común las lenguas es «que todas tienen que tener un lugar reservado para ese vocabulario, para poder con él hablar de realidades, pero que ese lugar, en cuanto común, está vacío ${ }^{74}$. Esto significa que cada lengua dispone de un «espacio» reservado para albergar sus palabras con significado y su propia Realidad, pero que no hay un vocabulario común que se exprese en todas las lenguas. Cada comunidad lingüística crea su propia Realidad basada en las palabras con significado de su lengua. Así, en fin, esta indeterminación del vocabulario semántico y su infinitud hacen que la Realidad esté siempre abierta al cambio y que hablando pueda esta cambiarse. Pues el lenguaje, por debajo de toda ideación de sí mismo que viene a convertirlo en Realidad, está también abierto al mundo cambiante y procesual que Nietzsche y Heráclito nos recuerdan. Sintetizando, ¿qué impide esa transformación de la Realidad? Por una parte, la confusión

72 El sector semántico o sector del vocabulario semántico hace referencia a la «parte» de una lengua donde se hallan las palabras con significado y que está en relación con los significados, sentido e interpretación de estas palabras y de los enunciados. Este es el único sector de la lengua que, según García Calvo, es infinito y no cerrado. García Calvo, A. op. cit., 1983, p. 400.

73 Ibidem, pp. 400-401.

${ }^{74}$ García Calvo, A. op. cit., 1996, pp. 233-234. 
del mundo en que se habla con el mundo de que se habla y la anulación del tiempo verdadero $-\mathrm{y}$, por tanto, del devenir y del cambio- que eso conlleva y, relacionado con esto, la «escritura, es decir, fijación del tiempo del habla en un espacio, por escrito" ${ }^{75}$; y, por otra parte, el manejo que las instituciones o los individuos pueden hacer del lenguaje y la hegemonía ideológica -sea efectuada conscientemente o noque estos imponen.

Frente a esta Realidad total e inmutable está lo que hay y que no existe ${ }^{76} \mathrm{y}$ que viene a deshacer el todo de la Realidad en lo $\sin f_{i n}{ }^{77}$. En este sentido encuentra García Calvo que el lenguaje, en cuanto que razona, está de alguna manera fuera de la Realidad. Y es que, mientras las ideas no pueden más que ser atemporales y «estar quietas", el hablar o el razonar es algo sucesivo y temporal, contrario, por tanto, a las ideas ${ }^{78}$ y no dinerario por darse -el lenguaje común y popular-a todos gratuitamente $^{79}$. La razón, así -si es capaz de razonar verdaderamente, y no limitarse a repetir las ideas e ideales impuestos-, puede descubrir la falsedad de la Realidad, puede ayudar a desvelar el carácter lingüístico, histórico, social y humano que esta tiene al hacernos ver que, efectivamente, las cosas podrían y pueden ser de otra manera y que la Realidad, en fin, como solía García Calvo repetir, no es todo lo que hay.

Recibido: noviembre de 2018. Aceptado: abril de 2019

75 García Calvo, A. Contra la Realidad (estudios de lenguas y de cosas), Lucina, Zamora, 2002, p. 208.

${ }^{76}$ García Calvo, A. op. cit., 1996, p. 251. García Calvo utiliza el verbo 'haber' para referirse a ese algo indefinido que hay sobre el que las ideas se asientan, mientras que el verbo 'existir' -creado en las escuelas filosóficas- lo reserva para las cosas reales. La justificación puede consultarse en el capítulo "De la contradicción en que se fundan 'existir' y 'realidad'» de la obra De Dios.

77 Según García Calvo, mientras que la Realidad crea un todo, esto es, un conjunto «debidamente definido», lo sin fin es aquello que escapa a la definición: “'Todo’ corresponderá al mundo de los significados, a la Realidad, mientras que 'sin fin' será de este mundo en que tú y yo estamos razonando acerca de lo que no sabemos, y por eso lo razonamos». Ibidem, p. 230.

78 García Calvo, A. op. cit., 1998, pp. 264-265.

79 García Calvo, A. op. cit., 1996, p. 20. 
